JEBIS: Jurnal Ekonomi dan Bisnis Islam Volume 5, No.2, Juli - Desember 2019

p-ISSN : 2442-6563 e-ISSN : 2525-3027

Page 123 - 133

\title{
THE INFLUENCE OF INTELLECTUAL CAPITAL ON RETURN ON ASSETS AND RETURN ON EQUITY SHARIA RURAL BANK 2015 - 2017 PERIOD
}

\author{
Qori Naufallita \\ Program Studi Ekonomi Islam, Fakultas Ekonomi dan Bisnis, Universitas Airlangga \\ Email: qori.naufallita-2014@feb.unair.ac.id \\ Achsania Hendratmi \\ Departemen Ekonomi Syariah, Fakultas Ekonomi dan Bisnis, Universitas Airlangga \\ Email: achsania.hendratmi@feb.unair.ac.id
}

ARTICLE HISTORY

Received:

2019-02-01

Accepted:

2019-12-05

Online available:

2019-12-31

Keywords:

Human Capital

Efficiency, Capital

Employed,

Structural Capital,

Profitability,

Islamic Rural

Banks,

Kata Kunci:

Human Capital

Efficiency, Capital

Employed,

Structural Capital,

Keuntungan, Bank

Pembiayaan

Rakyat Syariah
ABSTRACT

Purpose of this study is to determine the effect of Human Capital Efficiency, Capital Employed Efficiency, and Structural Capital Efficiency on Return On Assets and Return On Equity of Islamic Rural Banks period 2015-2017. This study uses a quantitative approach. Sampling technique is purposive sampling and there were 24 Islamic Rural Banks in Indonesia as subject of research. Analysis technique used is Panel Data Analysis. The results of this study indicate that CEE has a significant positive effect on ROA. Whereas HCE and SCE have no effect on ROA. Simultaneously HCE, CEE and SCE have a significant positive effect on ROA. In addition, the results of this study indicate that HCE and CEE have a significant positive effect on ROE, both partially and simultaneously.

\section{ABSTRAK}

Penelitian ini bertujuan untuk mengetahui pengaruh Human Capital Efficiency (HCE), Capital Employed Efficiency (CEE) dan Structural Capital Efficiency (SCE) pada Return On Assets dan Return On Equity Bank Pembiayaan Rakyat Syariah periode 2015-2017. Penelitian ini menggunakan pendekatan kuantitatif. Pengambilan sampel menggunakan purposive sampling dan terdapat 24 BPRS yang menjadi subyek penelitian. Teknik analisis menggunakan analisis Regresi Data Panel. Hasil penelitian menunjukkan CEE berpengaruh 
signifikan positif terhadap ROA. Sedangkan HCE dan SCE tidak berpengaruh terhadap ROA Secara simultan HCE, CEE dan SCE berpengaruh signifikan positif terhadap ROA. Selain itu, hasil penelitian ini menunjukkan bahwa HCE dan CEE berpengaruh signifikan positif terhadap ROE, baik itu secara parsial maupun simultan.

\section{PENDAHULUAN}

Selama beberapa tahun belakangan ini, perkembangan industri keuangan syariah di Indonesia berkembang cukup pesat. Terutama pada segmen perbankan syariah. Dengan adanya bank syariah dapat menjadi solusi bagi masyarakat dalam melakukan aktivitas keuangan, termasuk pembiayaan agar terbebas dari riba. Hal pelarangan riba tersebut terdapat dalam surat Al-Baqarah ayat 275 yang artinya:

"Orang-orang yang makan (mengambil) riba tidak dapat berdiri melainkan seperti berdirinya orang yang kemasukan syaitan lantaran (tekanan) penyakit gila. Keadaan mereka yang demikian itu, adalah disebabkan mereka berkata (berpendapat), sesungguhnya jual beli itu sama dengan riba. Padahal Allah telah menghalalkan jual beli dan mengharamkan riba. Orangorang yang telah sampai kepadanya larangan dari Tuhannya, lalu terus berhenti (dari mengambil riba), maka baginya apa yang telah diambilnya dahulu (sebelum datang larangan), dan urusannya (terserah) kepada Allah. Orang yang kembali (mengambil riba), maka orang itu adalah penghuni-penghuni neraka, mereka kekal di dalamnya".

(Departemen Agama RI, 2002)

Penafsiran surat Al-Baqarah ayat 275 menurut Ibnu Katsir. Melalui ayat ini, Allah menceritakan bahwa seorang pemakan riba akan dibangkitkan pada hari kiamat layaknya orang gila yang mengamuk seperti kesurupan setan. Ibnu Jarir meriwayatkan dari Ibnu Abbas juga berkata pada hari kiamat akan dikatakan kepada pemakan riba, "Ambillah senjatamu untuk berperang! (Allah dan Rasul-Nya menantang mereka untuk berperang dengan-Nya dikarenakan mereka tidak berkenan untuk meninggalkan sisa riba dan mereka tidak memiliki senjata apapun selain berharap perlindungan dari azab Allah) Ibnu Abbas membaca ayat ke 275 dari surat Al Baqarah tersebut, lalu dikatakan juga hal itu terjadi pada saat mereka dibangkitkan dari kubur". (Ar-rifa'i, 1999)

Dalam melaksanakan peran perbankan syariah sebagai lembaga intermediary keuangan, bank umum syariah dan unit usaha syariah terfokus pada pembiayaan dengan skala menengah atau besar. Sehingga, diperlukannya peran Bank Pembiayaan Rakyat Syariah guna melayani dan memenuhi kebutuhan pengusaha menengah, kecil, dan mikro dalam mendapatkan pembiayaan. Saat ini jumlah BPR syariah secara nasional sebanyak 167 dengan aset Rp10,5 trilun. Dari sisi kinerja BPRS berdasarkan modal inti (MI) bulan Juli pada tahun 2016, sebanyak 115 BPRS memiliki modal inti yang terbatas yaitu dibawah $6 \mathrm{M}$. 
BPRS yang memiliki modal inti dibawah $6 \mathrm{M}$ memiliki kecenderungan kinerja yang buruk bahkan hingga mengalami kerugian. Keterbatasan modal disebabkan oleh beberapa hal, yaitu :1) Kurangnya kemampuan PSP dalam menambah modal ; 2) PSP kurang memiliki komitmen dalam pengembangan BPRS ;3) Ekspansi kredit tidak diimbangi dengan penguatan modal. Yang pada akhirnya, mengakibatkan ketidakmampuan merekrut SDM yang berkualitas dan mengembangkan SDM yang berintegritas, tidak mampu dalam pengadaan IT yang handal, tidak mampu mengelola secara professional serta tidak mampu mengembangkan produk dan layanan yang bersaing (Otoritas Jasa Keuangan, 2018) .

Padahal Modal merupakan faktor penting dalam rangka membangun, mengembangkan dan mempertahankan berdirinya sebuah perusahaan. Perusahaan dapat berkembang dan bertahan dari gempuran globalisasi jika pertumbuhan modal finansial sejalan dengan pertumbuhan modal intelektual. (Ekowati, Rusmana, \& Mafudi, 2012). Menurut Pulic (1998) dalam (Ulum, Ghozali, \& Chariri, n.d.) tahun 2010 tujuan utama dalam ekonomi yang berbasis pengetahuan adalah untuk menciptakan value added. Sedangkan untuk dapat menciptakan value added dibutuhkan ukuran yang tepat tentang phisycal capital yaitu dana-dana keuangan serta intellectual potential dioresentasikan oleh karyawan dengan segala potensi dan kemampuan yang melekat pada mereka. Lebih lanjut Pulic menyatakan bahwa intellectual ability menunjukkan bagaimana kedua sumber daya physical capital dan intellectual potential telah secara efisien dimanfaatkan oleh perusahaan. Penelitian yang dilakukan (Tan, Plowman, \& Hancock, 2007) menunjukkan bahwa intellectual capital berpengaruh positif terhadap kinerja perusahaan, baik masa kini maupun masa mendatang. Selain itu penelitian ini juga menunjukkan bahwa rata-rata pertumbuhan intellectual capital (ROGIC) berhubungan positif dengan kinerja perusahaan di masa mendatang.

Berdasarkan penelitian terdahulu oleh Ousama (2015) menunjukkan bahwa keseluruhan komponen modal intelektual berpengaruh positif terhadap kinerja keuangan terutama pada profitabilitas bank Islam di Malaysia yang diukur dengan ROE. Hal yang menyebabkan keseluruhan modal intelektual lebih berpengaruh terhadap ROE dibanding ROA karena fakta bahwa mayoritas bank-bank Islam di Malaysia cenderung anak perusahaan bank konvensional dan bank asing. Pada penelitian ini juga menunjukkan pengaruh komponen Human Capital Effeciency terhadap profitabilitas bank syariah lebih tinggi dibandingkan Structural Capital Efficiency dab Capital Employed Efficiency.

Isanzu (2015) menjelaskan bahwa bank dapat memperoleh manfaat lebih dengan berinvestasi pada modal intelektual. Karena modal intelektual menunjukkan nilai tambah dan mampu meningkatkan profitabilitas perusahaan. Investasi sumber daya manusia sangat penting untuk mencapai tujuan bank. Modal intelektual merupakan variabel yang paling penting agar penggunaan aset secara fisik dan keuangan berjalan dengan efektif serta efisien. Bank harus berupaya lebih dalam berinvestasi pada modal 
struktural dengan menjadi lebih inovatif, berteknologi tinggi dan memiliki infrastruktur yang mendukung (Isanzua, 2015).

Berdasarkan penelitian yang dilakukan oleh Isanzu (2015) menunjukkan bahwa Human Capital Efficiency dan Capital Employed Efficiency berpengaruh signifikan positif terhadap kinerja keuangan yang diukur dengan ROA. Sedangkan Structural Capital Efficiency berpengaruh negatif terhadap kinerja keuangan. Hal ini dapat disebabkan karena bank dapat gagal dalam memanfaatkan modal struktural yang dimiliki. Uraian diatas menjelaskan bahwa pentingnya modal, baik itu modal fisik maupun modal intelektual dan semua komponen tersebut perlu diperhatikan guna menjaga keberlangsungan BPRS.

Berdasarkan latarbelakang diatas maka permasalahan penelitian ini yaitu apakah Human Capital Efficiency, Capital Employed Efficiency, Structural Capital Efficiency berpengaruh signifikan terhadap kinerja keuangan Bank Pembiayaan Rakyat Syariah (BPRS) baik secara parsial.

\section{LANDASAN TEORI}

Menurut Stewart, Intellectual Capital (modal intelektual) adalah materi intelektual pengetahuan, informasi, hak pemilikan intelektual, pengalaman yang dapat digunakan untuk menciptakan kekayaan (Ulum, 2009).

Secara umum para peneliti mengkategorikan intellectual capital terbagi menjadi tiga, yaitu : Human Capital, Capital Employed dan Structural Capital.Human Capital adalah modal intelektual perusahaan yaitu kompetensi, pengetahuan dan ketrempalian karyawan dimana karyawan tersebut bekerja. Human capital adalah kombinasi dari pengetahuan, skill, kemampuan melakukan inovasi dan kemampuan menyelesaikan tugas, meliputi nilai perusahaan, kultur dan filsafatnya. Perusahaan yang berhasil dalam mengelola pengetahuan karyawannya maka hal itu dapat meningkatkan human capital. Sehingga human capital merupakan kekayaan yang dimiliki oleh suatu perusahaan yang terdapat dalam tiap individu yang ada di dalamnya.

Capital Employed (CE) dapat didefinisikan sebagai total modal yang dimanfaatkan dalam aset tetap dan lancar dalam suatu perusahaan. Capital Employed Efficiency merupakan hubungan harmonis yang dimiliki antara perusahaan dengan para mitra kerjanya baik berasal dari para pemasok yang andal dan berkualitas juga dai pelanggan yang loyal dan merasa puas akan pelayanan perusahaan.Kualitas hubungan yang baik dan kemampuan untuk menciptakan pelanggan baru merupakan faktor kunci yang mendorong keberhasilan bagi suatu entitas.

Structural Capital dapat didefinisikan sebagai competitive intelligence, formula, sistem informasi, hak paten, kebijakan, proses, dan sebagainya, hasil dari produk atau sistem perusahaan yang telah diciptakan dari waktu ke waktu (Pulic, 1998; Firer dan Williams,2003). Structural Capital (SC) adalah infrastruktur yang dimiliki oleh suatu 
perusahaan dalam memenuhi kebutuhan pasar. Intelectual capital jenis ini terdiri dari rutinitas perusahaan, prosedur, sistem, budaya, dan database. Structural capital merupakan infrastruktur pendukung dari human capital sebagai sarana dan prasarana pendukung kinerja karyawan. Sehingga walaupun karyawan memiliki pengetahuan yang tinggi namun bila tidak didukung oleh sarana dan prasarana yang memadai, maka kemampuan karyawan tersebut tidak akan menghasilkan modal intelektual. (Ousama,2015).

Metode VAIC (Value Added Intellectual Coefficient) didesain untuk menyajikan informasi tentang value creation efficiency dari aset berwujud (tangible asset) dan aset tidak berwujud (intangible assets) yang dimiliki perusahaan.VAIC adalah koefisien efisiensi VA dari IC untuk perusahaan yang merupakan gabungan dari tiga koefisien efisiensi, yaitu CEE, HCE dan SCE. CEE adalah indikator efisiensi VA modal yang digunakan, HCE adalah indikator efisiensi VA modal manusia dan SCE merupakan indikator untuk efisiensi modal struktur. Rumusnya adalah sebagai berikut (Firer dan Williams, 2003): Persamaan 2. 1

\section{Menghitung Value Added (VA).}

VA $=$ OUT - IN

Dimana :

OUT = Output yaitu jumlah pendapatan keseluruhan produk dan jasa yang telah terjual ditambah pendapatan lain.

IN = Input yaitu beban penjualan dan biaya-biaya lain (selain beban gaji dan upah atau beban karyawan).

\section{Menghitung Human Capital Efficiency (HCE)}

$\mathrm{HCE}=\mathrm{VA} / \mathrm{HC}$

Dimana: Persamaan 2. 2

$\mathrm{VA}=$ Value Added

$\mathrm{HC}=$ Beban Gaji dan Upah atau Beban Karyawan

3. Menghitung Capital Employed Efficiency (CEE)

$\mathrm{CEE}=\mathrm{VA} / \mathrm{CE}$

Dimana: Persamaan 2. 3

$\mathrm{VA}=$ Value Added

$\mathrm{CE}$ = Modal yang tersedia (ekuitas, laba bersih)

4. Menghitung Structural Capital Effficiency (SCE).

SCE $=$ SC / VA

Dimana: Persamaan 2. 4

$\mathrm{SC}=$ Structural Capital adalah total dari VA dikurangi $\mathrm{HC}$

$\mathrm{VA}=$ Value Added

$\mathrm{HC}=$ Human Capital yaitu Beban Personalia atau Beban Gaji Karyawan. 


\section{METODE PENELITIAN}

Pendekatan yang digunakan dalam penelitian ini adalah pendekatan kuantitatif. Penelitian ini akan membuktikan pengaruh Human Capital Efficiency, Capital Employed Efficiency, dan Structural Capital Efficiency terhadap ROA dan ROE. Di dalam penelitian ini, peneliti menggunakan analisis regresi data panel. Dalam penelitian ini yang menjadi variabel endogen adalah ROA dan ROE serta variabel eksogennya adalah Human Capital Efficiency, Capital Employed Efficiency, dan Structural Capital Efficiency. Dalam penelitian ini menggunakan teknik sampling yaitu purposive sampling. Adapun Kriteria-kriteria yang digunakan dalam sampel ini adalah :

1. BPRS yang menerbitkan laporan bulan Desember tahun $2015-2017$

2.BPRS yang memiliki modal inti diatas $10 \mathrm{M}$ selama tahun 2015-2017.

Jumlah BPRS terdaftar sebanyak 167 BPRS. Berdasarkan kriteria tersebut selama periode penelitian, BPRS yang memenuhi kriteria sebanyak 24 perusahaan asuransi syariah pada periode penelitian 2015-2017, sehingga diperoleh observasi sebanyak 72 .

\section{HASIL DAN PEMBAHASAN}

1. Uji Hausman

Uji Hausman digunakan untuk memilih model estimasi terbaik antara FEM dan REM. Ketentuan uji hausman adalah apabila nilai signifikan<0.05 maka HO ditolak, dan apabila nilai signifikan>0.05 maka HO diterima (Ajija et al., 2011:53).

PengujianaModelaEstimasi ROA sebagai Variabel Dependen

Table 1

Hasil Uji Hausman ROA

\begin{aligned} \hline chi2(3) & $=(b-B)^{\prime}\left[\left(V_{-} b-V_{-} B\right)^{\wedge}(-1)\right](b-B) \\ & =3.71 \\$ Prob>chi2 & $=0.2942\end{aligned}$

Sumber : Olahan Penulis menggunakan STATA 14.0 (2019)

Hasil uji hausman pada gambar diatas menunjukkan bahwa model terbaik yang dapat digunakan dalam model pertama penelitian ini adalah REM. Hal tersebut dikarenakan nilai Probabilitas chi2 >0.05, sehingga menerima HO.

2. Pengujian Model Estimasi ROE sebagai Variabel Dependen

Table 2

Hasil Uji Hausman ROE

\begin{aligned} \hline $\operatorname{chi2}(3) & =(b-B)^{\prime}\left[\left(V_{-} b-V_{-} B\right)^{\wedge}(-1)\right](b-B) \\ & =2.93\end{aligned}$

Prob $>$ chi2 $=0.4022$

Sumber : Olahan Penulis menggunakan STATA 14.0 (2019) 
Hasil uji hausman pada gambar diatas menunjukkan bahwa model terbaik yang dapat digunakan dalam model pertama penelitian ini adalah REM. Hal tersebut dikarenakan nilai Probabilitas chi2 >0.05, sehingga menerima $\mathrm{H}$

3. Analisis Regresi Data Panel

Regresi Data Panel ROA sebagai Variabel Dependen

overall $=0.6828$

Random-effects GLS regression

between $=0.6282$

Number of obs $=72$

overall $=0.6828$

Table 3

Regresi Data Panel ROA sebagai Variabel Dependen

\begin{tabular}{lclcccc}
\hline ROA & Coef. & Std. Err. & $\mathbf{z}$ & P>|z| & [95\% Conf & Interval] \\
\hline HCE & .0031224 & .0035665 & 0.88 & 0.381 & -.0038678 & .0101125 \\
CEE & .0579601 & .0129955 & 4.46 & 0.000 & .0324893 & .0834308 \\
SCE & .0068314 & .007119 & 0.96 & 0.337 & -.0071214 & .0207843 \\
cons & .0153737 & .005536 & -2.78 & 0.005 & -.026224 & -.0045234 \\
\hline
\end{tabular}

Sumber : Hasil analisis regresi

Berdasarkan hasil analisis regresi data panel tabel 3 dapat diketahui bahwa persamaan regresi adalah sebagai berikut:

ROA $=-0,0153737+0,0031224 \mathrm{HCE}+0,0579601 \mathrm{CEE}+0,0068314 \mathrm{SCE}$

4. Regresi Data Panel ROE sebagai Variabel Dependen

Random-effects $\mathrm{GLS}$ regression

Number of obs $=72$

Table 4

Regresi Data Panel ROE Sebagai Variabel Dependen

\begin{tabular}{lcccccc}
\hline ROE & Coef. & Std. Err. & $\mathbf{z}$ & $\mathbf{P}>|\mathbf{z}|$ & [95\% Conf & Interval] \\
\hline HCE & -.107213 & .0415375 & -2.58 & 0.010 & -.188625 & -.0258009 \\
CEE & 1.102593 & .1514321 & 7.28 & 0.000 & .8057917 & 1.399395 \\
ROE & Coef. & Std. Err. & $\mathbf{z}$ & $\mathbf{P}>|\mathbf{z}|$ & [95\% Conf & Interval] \\
\hline SCE & .1139769 & .0823877 & 1.38 & 0.167 & -.0475 & .2754538 \\
cons & -.2250988 & .0657818 & -3.42 & 0.001 & -.3540289 & -.0961687 \\
\hline
\end{tabular}

Sumber : Hasil analisis regresi

Berdasarkan hasil analisis regresi data panel tabel 4 dapat diketahui bahwa persamaan regresi adalah sebagai berikut

ROE $=-0,2250988-0,107213 \mathrm{HCE}+1,102593 \mathrm{CEE}+0,1139769 \mathrm{SCE}$

5. Analisis Koefisien Determinasi (R2)

Koefisien Determinasi ROA sebagai Variabel Dependen 
Table 5

Regresi Data Panel ROA sebagai Variabel Dependen

\begin{tabular}{ccc}
\hline Total Panel Obs & R2 & Prob (F Statistic) \\
\hline $\mathbf{7 2}$ & 0,6282 & 0,000 \\
\hline
\end{tabular}

Sumber : Hasil analisis regresi

Berdasarkan tabel diatas dapat diketahui bahwa nilai koefisien determinasi sebesar 0,6282 atau 62,82\%. Hal tersebut menunjukkan bahwa variabel HCE, CEE dan SCE mampu menjelaskan variabel ROA sebesar $62,82 \%$, sedangkan sisanya dipengaruhi oleh faktor lain diluar variabel yang diteliti. Koefisien Determinasi ROE sebagai Variabel Dependen

Table 6

Regresi Data Panel ROE sebagai Variabel Dependen

\begin{tabular}{ccc}
\hline Total Panel Obs & R2 & Prob (F Statistic) \\
\hline $\mathbf{7 2}$ & 0,5994 & 0,000 \\
\hline
\end{tabular}

Sumber : Hasil analisis regresi

Berdasarkan tabel diatas dapat diketahui bahwa nilai koefisien determinasi sebesar 0,5994 atau 59,94\%. Hal tersebut menunjukkan bahwa variabel HCE, CEE dan SCE mampu menjelaskan variabel ROA sebesar 59,94\%, sedangkan sisanya dipengaruhi oleh faktor lain diluar variabel yang diteliti.

Table 7

Uji t pada ROA sebagai Variabel Dependen

\begin{tabular}{lllll}
\hline ROA & Coef. & Std. Err. & Z & P>|z| \\
\hline HCE & .0031224 & .0035665 & 0.88 & 0.381 \\
CEE & .0579601 & .0129955 & 4.46 & 0.000 \\
SCE & .0068314 & .007119 & 0.96 & 0.337 \\
_cons & -.0153737 & .005536 & -2.78 & 0.005 \\
\hline \multicolumn{4}{c}{ Sumber : Olahan data penulis dengan STATA 14.0 (2019) }
\end{tabular}

Pengujian Hipotesis 2a: HCE berpengaruh terhadap ROA

Berdasarkan hasil analisis pada tabel 49 nilai koefisien HCE adalah 0.0031224 , dan prob. sebesar 0.381 atau $>0.005$. Hal ini menunjukkan bahwa variabel HCE tidak berpengaruh signifikan terhadap ROA, atau dengan kata lain hipotesis 2a ditolak.

Tidak berpengaruhnya HCE terhadap ROA menunjukkan bahwa karyawan BPRS belum mampu menggunakan pengetahuan dan keterampilannya dengan baik sehingga tidak menghasilkan nilai tambah bagi BPRS. Selain itu terdapat indikasi bahwa besar gaji dan tunjangan yang diberikan belum mampu memberi motivasi pada karyawan dalam meningkatkan laba BPRS 
Pengujian Hipotesis 3a: CEE berpengaruh terhadap ROA

Berdasarkan hasil analisis pada tabel 4.9 nilai koefisien CEE adalah 0.0579601 , dan prob. sebesar 0,000 atau $<0.005$. Hal ini menunjukkan bahwa variabel CEE berpengaruh signifikan terhadap ROA, atau dengan kata lain hipotesis 3a diterima.

Hal ini menunjukkan bahwa BPRS dapat mengelola dana yang tersedia untuk dapat meningkatkan nilai tambah BPRS yang pada akhirnya mampu meningkatkan ROA. Sehingga dapat dikatakan bahwa BPRS telah menggunakan ekuitasnya secara efisien guna meningkatkan laba BPRS dan meningkatkan efisiensi penggunaan asset yang dimiliki. Hasil penelitian ini sejalan dengan penelitian Chen (2005) dan Isanzu (2017) yang menunjukkan bahwa CEE berpengaruh signifikan terhadap ROA

Pengujian Hipotesis 4a : SCE berpengaruh terhadap ROA

Berdasarkan hasil analisis pada tabel 4.9 nilai koefisien SCE adalah 0,006814, dan prob. sebesar 0,337 atau >0.005. Hal ini menunjukkan bahwa variabel SCE tidak berpengaruh signifikan terhadap ROA, atau dengan kata lain hipotesis 4a ditolak. Hal ini menunjukkan bahwa BPRS belum mampu memenuhi proses rutinitas BPRS dan strukturnya untuk mendukung usaha karyawan agar dapat menghasilkan kinerja intelektual dan kinerja bisnis secara optimal, misalnya sistem operasional, dan budaya organisasi

6. Uji t pada ROE sebagai Variabel Dependen

Table 8

Uji T Pada ROE Sebagai Variabel Dependen

\begin{tabular}{lllll}
\hline ROE & Coef. & Std. Err. & \multicolumn{1}{c}{$\mathbf{Z}$} & \multicolumn{1}{c}{$\mathbf{P}>|\mathbf{z}|$} \\
\hline HCE & -.107213 & .0415375 & -2.58 & 0.010 \\
CEE & 1.102593 & .1514321 & 7.28 & 0.000 \\
SCE & .1139769 & .0823877 & 1.38 & 0.167 \\
_cons & -.2250988 & .0657818 & -3.42 & 0.001 \\
\hline
\end{tabular}

Sumber : Olahan penulis dengan STATA 14.0 (2019)

Pengujian Hipotesis $2 b$ : HCE berpengaruh terhadap ROE

Berdasarkan hasil analisis pada tabel 4.10 nilai koefisien HCE adalah - 0.107213 , dan prob. sebesar 0.010 atau $<0.005$. Hal ini menunjukkan bahwa variabel HCE berpengaruh signifikan terhadap ROE, atau dengan kata lain hipotesis $2 \mathrm{~b}$ diterima.

Hasil penelitian ini sejalan dengan Pramelasari (2010) dan Turmudi (2017) menunjukkan bahwa HCE berpengaruh signifikan negatif terhadap ROE. Hal ini dikarenakan anggaran beban gaji karyawan yang tinggi tanpa diimbangi dengan pelatihan dan training maka berdampak pada penurunan produktivitas karyawan. Sehingga mengakibatkan adanya penurunan kontribusi pendapatan dan rendahnya tingkat pengembalian modal BPRS.

Pengujian Hipotesis $3 b$ : CEE berpengaruh terhadap ROE

Berdasarkan hasil analisis pada tabel 4.10 nilai koefisien CEE adalah 1.102593, dan prob. sebesar 0,000 atau $<0.005$. Hal ini menunjukkan bahwa variabel CEE berpengaruh signifikan terhadap ROE, atau dengan kata lain hipotesis $3 \mathrm{~b}$ diterima. Hal 
ini menunjukkan bahwa dana yang tersedia mampu meningkatkan nilai tambah bagi BPRS serta meningkatkan tingkat pengembalian modal kepada pemegang saham Pengujian Hipotesisi $4 b$ : SCE berpengaruh terhadap ROE

Berdasarkan hasil analisis pada tabel 4.10 nilai koefisien SCE adalah 0,1139769, dan prob. sebesar 0,167 atau $>0.005$. Hal ini menunjukkan bahwa variabel SCE tidak berpengaruh signifikan terhadap ROE, atau dengan kata lain hipotesis $4 \mathrm{~b}$ ditolak.

Hal ini menunjukkan bahwa BPRS belum mampu memenuhi proses rutinitas BPRS dan strukturnya untuk mendukung usaha karyawan agar dapat menghasilkan kinerja secara optimal guna meningkatkan tingkat efisiensi penggunaan modal untuk menghasilkan laba bagi pemegang saham.

\section{SIMPULAN}

Berdasarkan uji simultan yang telah dilakukan, diketahui bahwa secara simultan varibel HCE, CEE, dan SCE berpengaruh signifikan terhadap ROA. Hasil pengujian tersebut ditunjukkan melalui nilai Uji $F$ sebesar 0.000 atau $<0.005$. Hal ini dapat diartikan bahwa secara keseluruhan komponen intellectual capital dapat mempengaruhi tingkat efisiensi penggunaan aset guna menghasilkan laba.

Hasil ini sejalan dengan penelitian Chen et al.(2005) yang menggunakan model Pulic (VAIC) untuk menguji hubungan antara Intellectual Capital dengan nilai pasar dan kinerja keuangan perusahaan dengan menggunakan sampel perusahaan Publik di Taiwan. Hasilnya menunjukkan bahwa IC berpengaruh positif terhadap nilai pasar dan kinerja keuangan perusahaan.

\section{DAFTAR PUSTAKA}

Ar-rifa'i, M. N. (1999). Kemudahan Dari Allah - Ringkasan Tafsir Ibnu Katsir Jilid 1. Gema Insani.

Aritonang, Q. A. S., MUHARAM, H., \& SUGIONO, S. (2016). PENGARUH INTELLECTUAL CAPITAL TERHADAP KINERJA KEUANGAN (Studi Pada Perusahaan Non Keuangan yang Terdaftar di Bursa Efek Indonesia Periode Tahun 2012-2014) (Doctoral dissertation, Diponegoro University).

Chen, M. (2005). Sebuah penyelidikan empiris hubungan antara nilai pasar intelektual modal dan, 159-176.

Ekowati, S., Rusmana, O., \& Mafudi. (2012). Pengaruh Modal Fisik, Modal Finansial, dan Modal Intelektual Terhadap Kinerja Perusahaan Pada Perusahaan Manufaktur di Bursa Efek Indonesia, pp 1-23. http://doi.org/10.1016/S01406736(09)62015-8

Ekawati, K., \& Shofawati, A. (2019). FAKTOR-FAKTOR YANG MEMPENGARUHI TINGKAT MARGIN MURABAHAH PADA INDUSTRI PERBANKAN SYARIAH PERIODE 20122017. Jurnal Ekonomi dan Bisnis Islam (Journal of Economics and Business Islamic), 5(1), 50-67.

Firer, S., \& Mitchell Williams, S. (2003). Intellectual capital and traditional measures of corporate performance. Journal of intellectual capital, 4(3), 348-360.

Isanzua, J. N. (2015). Impact of Intellectual Capital on Financial Performance of Banks 
in Tanzania. Journal of International Business Research and Marketing, 1(1).

Isanzu, J. S. (2017). The impact of credit risk on the financial performance of Chinese banks. Journal of International Business Research and Marketing, 2(3), 14-17.

Otoritas Jasa Keuangan. (2018). Statistik Perbankan Syariah. Retrieved from www.ojk.go.id

Ousama, A. A. and A. H. F. (2015). Intellectual capital and financial performance of Islamic banks. Int. J. Learning and Intellectual Capital, 2(1).

Pramelasari, Y. M., \& PRASTIWI, A. (2010). Pengaruh intellectual capital terhadap nilai pasar dan kinerja keuangan perusahaan (Doctoral dissertation, Perpustakaan FE UNDIP).

Rusmita, S. A., \& Cahyono, E. F. (2016). PENGARUH VARIABEL EKONOMI MAKRO, PEMBIAYAAN DARI BANK UMUM SYARIAH DAN IKNB SYARIAH TERHADAP EKSPOR INDONESIA TAHUN NOVEMBER 2013-APRIL. NISBAH: JURNAL PERBANKAN SYARIAH, 2(2), 235-242.

SW, I. F., \& Firmansyah, R. (2012). Pengaruh intellectual capital terhadap kinerja keuangan perusahaan (Studi empiris perusahaan LQ 45). Jurnal Dinamika Akuntansi, 4(1).

Tan, H. P., Plowman, D., \& Hancock, P. (2007). Intellectual capital and financial returns of companies. Journal of Intellectual Capital, 8(1), 76-95. http://doi.org/10.1108/14691930710715079

TURMUDI, A. Z. (2017). ANALISIS PENGARUH INTELLECTUAL CAPITAL TERHADAP RETURN ON EQUITY (ROE) DAN RETURN ON ASSET (ROA) PADA PERUSAHAAN YANG MASUK DALAM INDEKS LQ45 (Doctoral dissertation, STIE PERBANAS SURABAYA).

Ulum, I. (2013). Model Pengukuran Kinerja Intellectual Capital Dengan IB-VAIC Di Perbankan Syariah. Jurnal Penelitian Sosial Keagamaan, 7(1).

Ulum, I., Ghozali, I., \& Chariri, A. (n.d.). Intellectual Capital Dan Kinerja Keuangan Perusahaan ; Suatu Analisis Dengan Pendekatan Partial Least Squares. Intellectual Capital Dan Kinerja Keuangan Perusahaan; Suatu Analisis Dengan Pendekatan Partial Least Squares, 19(19), 1-31. 